\title{
Normativity in joint action
}

\author{
Javier Gomez-Lavin ${ }^{1}$ | Matthew Rachar ${ }^{2}$
}

${ }^{1}$ Department of Philosophy, The University of Pennsylvania, Philadelphia, Pennsylvania

${ }^{2}$ Philosophy Program, The Graduate Center, New York, New York

Correspondence

Javier Gomez-Lavin, Department of Philosophy, The University of Pennsylvania, Philadelphia, Pennsylvania 19104.

Email: jgomezlavin@gmail.com
The debate regarding the nature of joint action has come to a stalemate due to a dependence on intuitional methods. Normativists, such as Margaret Gilbert, argue that actionrelative normative relations are inherent in joint action, while non-normativists, such as Michael Bratman, claim that there are minimal cases of joint action without normative relations. In this work, we describe the first experimental examinations of these intuitions, and report the results of six studies that weigh in favor of the normativist paradigm. Philosophical ramifications and further extensions of this work are then discussed.

\section{KEYWORDS}

Bratman, commitment, Gilbert, joint action, normativity, shared intention

\section{INTRODUCTION}

While sitting at a café you notice two people come around the corner, walk down the street largely in lockstep, and then turn out of view at the next intersection. Do they just happen to be walking next to each other or are they walking together? If you are a jealous spouse, or a police officer conducting surveillance, the answer to this question takes on special importance, but even for a disinterested observer there is an intuitive difference between these two possibilities; acting together appears to require more than parallel action in close proximity. ${ }^{1}$ However, what accounts for this difference? What conditions need to be satisfied for two people to do something together?

In the philosophical literature on joint action, several theories using the related notions of collective, shared, joint, or we-intentions have been proposed to regiment this difference, explain how joint actions are initiated, executed, and maintained, and clarify the relation between individual and collective mentality and action. Although there is almost universal agreement on the importance of the distinction drawn above, and the partial irreducibility of the collective to the individual, these views vary widely on several issues. One axis along which these theories differ is the role of normative relations such as obligations, rights, and entitlements between the participants in the constitution of joint

\footnotetext{
1 Thanks to Hans Bernhard Schmid (personal communication) for the examples.
} 
action (Schmid, 2009, p. 53). Normativists, including Margaret Gilbert (2006, 2009, 2013), Abraham Roth (2004, 2014) and Anthonie Meijers (2003), argue that joint actions always involve these normative relations. Part of what it is for an action to count as a genuine case of acting together is that obligations, rights, and entitlements exist between the participants. Gilbert, for example, states that "obligations and entitlements_-not necessarily moral obligations and rights-are inherent in acting together" (2013, p. 53). In contrast, non-normativists including John Searle (1990, 2010), Michael Bratman (2006, 2009, 2013) and The Tuomelas (Tuomela, 2005; Tuomela \& Tuomela, 2003), argue that joint action only involves some structure of psychological attitudes as an essential feature. It is therefore possible to have a joint action without any genuine commitments, obligations, or entitlements. The following quote from Bratman is representative:

Now, I agree that mutual obligations and entitlements are extremely common in cases of modest sociality, though I think that these will normally be familiar kinds of moral obligation...But...I am not convinced that such obligations are essential to modest sociality (Bratman, 2009, pp. 151-152).

For Bratman, cases of modest sociality involve shared intentions, which is enough to distinguish them from individual action. There are at least two areas of substantive disagreement between Bratman and Gilbert: (1) Are normative relations inherent in joint action, even in cases of modest sociality? And, (2) Are these normative relations specific to the joint action in question, or are they dependent on general, global, moral conceptions?

To address these questions, both normativists and non-normativists employ thought experiments featuring vignettes of people undertaking some project together, such as walking together, pushing a car, making hollandaise sauce, playing a symphony, and so on. These thought experiments are meant to elicit intuitions about the presence or absence of normative relations between the participants of the joint action. Currently, both groups take their examples to be conclusive. On the non-normativist side, Bratman states his case as follows:

Consider a variant of the example of walking together highlighted in Gilbert's work. Suppose you and I are independently walking down Fifth Avenue. We spot each other on 65th Street, and we briefly walk together, chatting, until, as it happens, you peel off at 59th Street. We do not merely walk individually along the same stretch of street and at the same time. Rather, we intentionally walk together for this brief time, and we briefly have a shared intention to walk together. Nevertheless, it seems strained to insist [our emphasis], barring the introduction of further features to the story, that either has an obligation to the other not to opt out without the other's permission $(2006, \mathrm{p}$. 7).

Based on this example, Bratman concludes that there are instances of joint action that do not involve normative commitments, but still meet the requirements for modest sociality. Arguing for the normativists, Gilbert tells the following story:

Suppose that Heinrich and Andrea are going for a walk together... Suppose now that Heinrich suddenly claps his hand to his brow, says "Oh No!" and, without further ado, starts walking rapidly away from Andrea. Andrea may not be disappointed that he has gone. Barring special background understandings, however, she will understand thatto put it somewhat abstractly-the manner of his going involved a mistake [original emphasis]. It is a mistake by virtue of the fact that they were walking together...Given that this is so, Andrea evidently understands that by virtue of their walking together she 
has a right of some kind to Heinrich's continuing to walk alongside her...together with the standing to issue related rebukes and demands (2013, pp. 25-26).

Gilbert is explicit about her methodology of examining these quotidian cases of acting together, and claims that her "warrant for the description is informal observation including self-observation" (2013, p. 24). On this basis, she takes it as demonstrated that even minimal joint actions inherently involve normative relations.

Despite the similarity of these two examples, Bratman and Gilbert come to opposite conclusions about fundamental aspects of acting together, and each appears as certain of their position as the other. Given their certainty and the intuitional methodology involved in arguing for each position, it is perhaps surprising that there is a dearth of empirical research on said intuitions. Furthermore, although there have been fruitful interactions between the normativists and non-normativists, especially between Bratman $(2009,2013)$ and Gilbert $(2009,2013)$, it appears that the philosophical discussion has reached a stalemate.

To remedy this, our paper takes an empirical approach to examine common intuitions about everyday conceptions of acting together. We are interested in people's ability to detect the presence of normative relations as a function of increasing evidence of joint action, or, in the converse case, their ability to infer the pre-existence of a joint action from some normative interaction. Here, we expect to find that judgments regarding the existence of normative relations will track perceived joint actions, and vice versa. That is, given cases of joint action, participants will judge that there are normative relations between the actors, and given cases involving normative relations, participants will judge that the actors are acting together. Furthermore, we are also interested in the difference between normative relations that may depend on a particular joint action, and those that may be accounted for by general moral considerations. Gilbert, for example, distinguishes between obligations arising from joint commitments and moral obligation (2006, pp. 157-159) and argues that the normativity that arises in joint action is present even in cases that are morally objectionable (2009, pp. 183-184). In contrast, Bratman argues that any obligation or entitlement in joint action "will normally be familiar kinds of moral obligation" (2009, p. 151). ${ }^{2}$ On this issue, we expect that individuals will recognize obligations between actors engaging in behavior that they take to be immoral.

To test these hypotheses, we have developed six studies. Study 1 examines whether joint actions that involve one actor helping another generate an obligation to notify, where the helper must notify the person being helped that they are leaving the joint action. In Study 2, we reverse the perspective, asking participants whether the actor being helped has standing to rebuke the helper for leaving the joint action. In Studies 3 and 4, we modify these cases by removing the helping element and checking whether the standing to rebuke and the obligation to notify, respectively, are affected. In Study 5, we invert the treatment to see whether participants infer that two people are acting together when there is evidence of normative relations between them. Finally, in Study 6, we test whether people attribute obligations to actors taking part in an action judged to be immoral.

The remainder of the paper is structured as follows: Sections 1-6 detail the corresponding studies. Section 7 discusses various philosophical consequences, both for the normativist and nonnormativists in general, and Bratman and Gilbert in particular, and ends by considering ideas for the direction of future empirical research on joint action. Section 7 concludes.

\footnotetext{
2 Although Bratman does qualify this with "normally" here, it is clear from the summation of his statements on the issue that moral obligation is the only kind of obligation in joint action, and that they are only present in some joint actions (2006, pp. 7-8; 2009, pp. 151-152; 2013, pp. 110-111).
} 


\section{I STUDY 1: THE OBLIGATION TO NOTIFY IN THE CAR PUSHING CASE}

This study focuses on the impact of helping behavior in an instance of liminal joint action. The vignette (q.v., Appendix S2 for the full prompts, Supporting information) is based on a thought experiment discussed by John Searle (1990, p. 404), who relates the story as follows:

I see a man pushing a car in the street in an effort to get it started; and I simply start pushing with him. No words are exchanged and there is no convention according to which I push his car. But it is a case of collective behavior. In such a case, "I am pushing only as part of our" pushing.

Although Searle does not explicitly side with the non-normativists in this example, he does so in later work (2010, cf., p. 50), and this case is often taken as an example in which there is joint action but no normative relations. ${ }^{3}$

Because we are interested in the relation between joint action and normativity, we constructed three variations of the prompt, each increasing the evidence of joint action between two fictional actors, Will and Alexander. Every condition begins with Will's car broken down on the side of the road. Participants were then randomly assigned to one of our three conditions, producing a $3 \times 1$ between-subjects design. In our control condition, where we give no evidence of any joint action among the actors, Alexander merely walks by without helping Will. Our second condition features liminal, or low, joint action, where Alexander stops to help Will for a few brief seconds and then leaves without saying anything. Our third and last condition features high evidence of joint action, with Alexander vocalizing his desire to help, "Here, let me help," before helping Will push the car for many minutes and then leaving without saying anything. After reading the prompt, participants were asked a series of questions relating to the dependent measures investigated.

Study 1 generates two predictions that follow the normativist account. First, participants should indicate that there is a greater obligation for Alexander to notify Will that he is leaving in both the low and high joint action conditions compared to the control condition. Second, if our conditions genuinely vary by increasing evidence of joint action, then participants should give increasing ratings of togetherness from the control to the low and high joint action conditions.

\section{1 | Method}

One hundred and fifty-three American adults (49\% self-identified as female) were recruited online via Amazon Mechanical Turk. Seven additional participants were excluded from analyses for failing to complete the study.

Participants were randomly assigned to one of three conditions, producing a $3 \times 1$ betweensubjects design. As mentioned above, in our control, or no joint action condition, 46 participants were presented with a word prompt in which Alexander did not help Will push his car. In the low joint action condition, 55 participants read a prompt where Alexander helps Will push his car for a few seconds. Finally, in the high joint action condition, 52 participants read a prompt where Alexander vocalizes his desire to help, and does so for many minutes before leaving. In each condition, participants were instructed to answer the same four questions detailed below, presented in random order, which constitute our dependent measures. Afterwards, participants were directed to answer a series of demographic questions (q.v., Appendix S2).

\footnotetext{
${ }^{3}$ Examples of this kind go at least as far back as Hume's case of two men rowing a boat without explicit agreement (1740/1976, p. 490).
} 


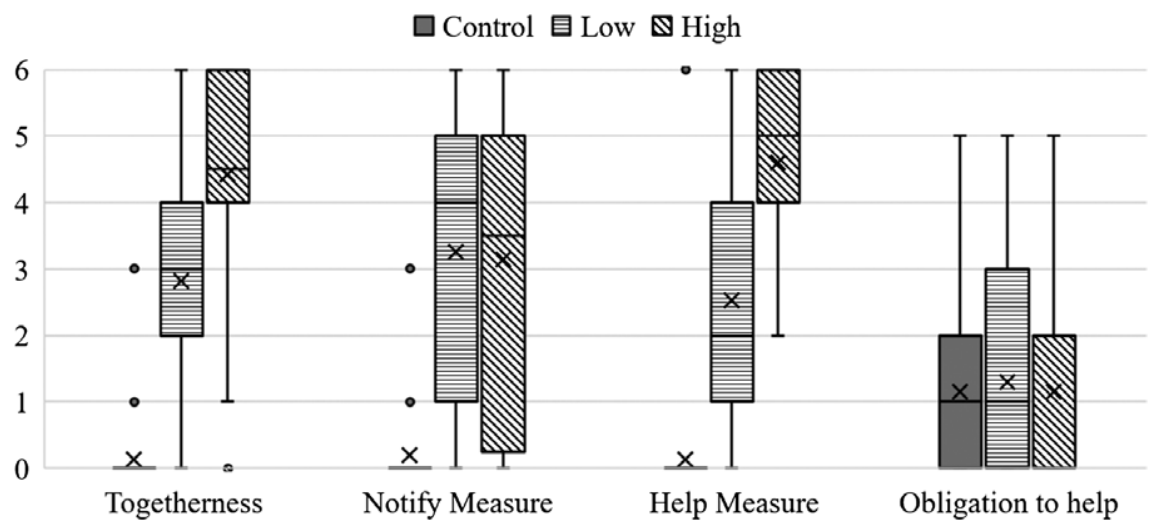

FIGURE 1 Box-and-whisker plot comparing dependent measures across our three conditions in Study 1. Bolded horizontal lines represent the medians of our measures, while "X" represents the means. Points represent furthest outliers where available

1. Togetherness measure: "Were Alexander and Will acting together?", anchored at 0 ("Not at all") and 6 ("Totally working together"). This measure serves as our first manipulation check.

2. Notification measure: "Should Alexander, the passer-by, notify Will that he is walking off?", anchored at 0 ("No obligation at all to notify") and 6 ("Total obligation to notify"). This measure tests for the presence of normative relations between the characters in the prompt.

3. Helping measure: "To what extent did Alexander help Will?", anchored at 0 ("Not at all") and 6 ("Did everything he should"). This measure serves as our second manipulation check.

4. Obligation to help: "Does Alexander have an obligation to help Will?", anchored at 0 ("No obligation to help") and 6 ("Total obligation to help"). This measure tests for the presence of global moral considerations.

\section{2 | Results}

We first tested participant ratings in our four measures for normality; however, KolmogorovSmirnov and Shapiro-Wilk's tests showed that participant scores were not normally distributed (all $p<.05)$. We then used a series of non-parametric tests to analyze the data: Kruskal-Wallis comparisons between our three conditions, pairwise comparisons adjusted by Bonferroni corrections for multiple tests, and Spearman's Rho for correlations. ${ }^{4}$

Results were generally consistent with our two normativist predictions (see Figure 1). Our manipulation, increasing the evidence of joint action between conditions, was successfully tracked by our participants and yielded a significant main effect, $H(2)=100.16, p<.001 .^{5}$ Median tendencies (hereafter "Mdns") of participants' scores in our togetherness measure increased between our conditions with values of 0 in our control, compared to 3 in our low joint action and 4.5 in our high joint action condition. Corrected pairwise comparisons showed that all our conditions significantly differed from one another (all $p \leq .001$ and all effect sizes $r \geq .35$; see Appendix S1 for more details of all pairwise comparisons throughout the paper). Hence, our manipulation significantly increased perceptions of togetherness across our conditions.

Similarly, participants' ratings in our notification measure were significantly higher between both our low and high joint action conditions (Mdns $=4$ and 3.5 respectively) and our control condition

\footnotetext{
${ }^{4}$ Given the relative scarcity of non-parametric models used in most previous experimental philosophy work, we have formatted our results following those presented by Diaz, Viciana and Gomila's recent (2017) paper on the seminal side-effect, or "Knobe", effect.

${ }^{5} E_{R}^{2}=.65$; refer to Appendix S1 for an explanation of how our effect sizes (including " $r$ " and " $r$ ") were calculated.
} 
$(M d n=0)$, yielding a significant effect between conditions, $H(2)=61, p<.001 .^{6}$ As one might infer from the slight difference among our median scores, corrected pairwise comparisons did not yield a significant difference between low and high joint action conditions, but we did find significant differences between these conditions and our control (both comparisons $p \leq .001$ and $r \geq .66$ ). Participants did not judge that there was a greater obligation to notify in the high joint action condition than in the low joint action condition, but they did judge that there was an obligation to help in both of our joint action conditions compared with our control condition.

Participants' ratings of whether Alexander helped Will were highly correlated with their ratings of the extent to which the characters were acting together, $r_{s}=0.847, p<.001$. Unsurprisingly, results from our helping measure follow the same pattern as our togetherness measure, with median scores significantly increasing from our control (0) to our low (2) and high joint action conditions (5). ${ }^{7}$ Corrected pairwise comparisons again showed that all our conditions significantly differed from one another. ${ }^{8}$

At the same time, there were no significant differences between our conditions for our obligation to help measure. The means of participants' scores give further descriptive evidence that participants did not judge there to be any global moral obligation for Alexander to help Will (see Figure 1).

\section{3 | Discussion}

Overall, these findings suggest that there is an easily recognized phenomenon corresponding to the technical notion of joint action. ${ }^{9}$ Participants clearly distinguished the control case from either of the joint action cases when asked whether the individuals are acting together. This finding is supported by previous survey research conducted by Deborah Tollefsen and colleagues, which found that participants readily identify situations (e.g., playing poker) that are a priori categorized as involving joint action (Tollefsen, Kreuz \& Dale, 2014). Furthermore, the findings appear to support the normativist account. When there is some evidence of two agents acting together, people judge that one actor in the joint action has an obligation to notify the other when they plan to terminate the joint action, and that the specific obligation is separable from any general moral obligations to help a stranger in need. This is shown by the pronounced difference between the control condition and the joint action conditions on the obligation to notify dependent measure and the lack of any significant differences between the means for our general obligation to help dependent measure.

\section{I STUDY 2: THE RIGHT TO REBUKE IN THE CAR PUSHING CASE}

In the previous study, we looked at only one side of the normative relation between contributors to a joint action. However, the action-specific normative relations for which the normativists argue are bidirectional. It is not only that one actor has an obligation to notify the other; each actor also has the standing to rebuke the other for their failure to complete their part of the action or to fulfill their action-specific obligations. Using the same prompts and design, we merely changed one of our dependent measures to reflect the change in perspective from an obligation on the part of the

\footnotetext{
${ }^{6} E_{R}^{2}=.4$.

${ }^{7} H(2)=105.106, p<.001, E_{R}^{2}=.69$.

${ }^{8}$ All $p \leq .001$ and all effect sizes $r \geq .42$ See Table 1 in Appendix S1.

9 Though many of our means are "below the mid-point" of our scale (i.e., 3 out of 6), what we are primarily concerned with is the relative differences between our conditions. Recall that the highest end of our scales was coded as "total" obligation or "totally" working together, thus it is not surprising that such language may have pushed scores below the mid-point. However, enough variability was obtained to result in significant differences between mean scores. Thanks to John Greenwood for these observations.
} 


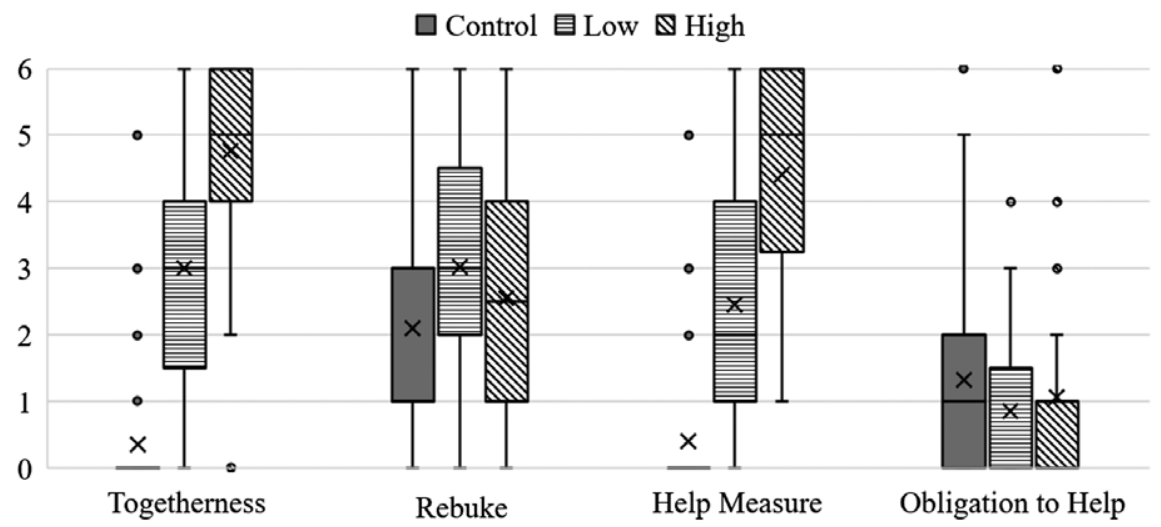

FIGURE 2 Box-and-whisker plot comparing dependent measures across our three conditions in Study 2. Bolded horizontal lines represent the medians of our measures, while "X" represents the means. Points represent furthest outliers where available

contributor who leaves, to the right of the participant to rebuke a contributor who leaves without satisfying their obligation. The aim of this study was to see whether this bidirectionality obtains. If the normativist account is correct, participants should be more willing to allow a rebuke in the conditions that have instances of joint action than in our control condition.

\section{1 | Method}

One hundred and fifty-two American adults (51\% self-identified as female) were recruited online via Amazon Mechanical Turk. As in Study 1, participants were randomly assigned to one of three conditions, producing a $3 \times 1$ between-subjects design (all prompts were identical to those used in Study 1). Fifty-one participants were assigned to our control condition, with 49 and 52 assigned to our low and high joint action conditions, respectively. Participants were given the same dependent variable and demographic measures, except for the question concerning Alexander's obligation to notify, replacing it with a Rebuke Measure. Here, we asked participants "How acceptable would it be for Will to call out to Alexander and say 'Hey, where are you going?'” As with Study 1, participants responded according to a seven-point scale anchored at 0 ("Totally unacceptable") and 6 ("Totally acceptable").

\section{2 | Results}

Again, participants' scores were not normally distributed (Kolmogorov-Smirnov and Shapiro-Wilk's tests all $p<.05$ ), necessitating the use of non-parametric tests. Additionally, our two manipulation checks confirmed that participants correctly tracked increasing levels of togetherness and helping across our conditions. ${ }^{10}$ Mirroring our findings for Study 1, corrected pairwise comparisons revealed that participant scores for these two measures significantly increased between conditions (see Figure 2 and Appendix S1, Table 2). ${ }^{11}$ There were no significant differences in participants' ratings for our obligation to help measure across conditions, confirming that in these car-pushing cases there is no moral obligation to provide help. ${ }^{12}$

\footnotetext{
${ }^{10}$ Kruskal-Wallis independent samples measures: $H(2)=92.89, p<.001, E_{R}^{2}=.61$ for our togetherness measure and $H(2)=93.15$, $p<.001, E_{R}^{2}=.62$ for our helping measure.

11 All pairwise comparisons $p \leq .001, r \geq .35$.

${ }^{12} H(2)=1.514, p=.469$.
} 
Results for our new rebuke measure, on the other hand, differed from our predictions. Increasing evidence of joint action in our conditions did not yield a main effect on participants' ratings of the permissibility of rebuke; however, a closer examination showed that participants judged that it was significantly more acceptable for Will to "call out" Alexander in the low joint action condition $(M d n=3)$ than in the control condition $(M d n=1) .{ }^{13}$ Furthermore, the effect size of this difference $\left(r_{m}=.24\right)$ is far smaller than what was obtained with our notify measure in Study 1 between the same two conditions $(r=.7)$. Other comparisons between conditions did not reach significance.

\section{3 | Discussion}

There are at least two potential explanations of this result. First, contrary to our hypothesis, the bidirectionality that the normativists propose may not be fully recognized by folk intuitions. This is suggested by two facts: there is no significant difference in the acceptability of rebuke between the control condition and the high joint action condition, and the difference between the control condition and low joint action condition does not match the strength of our notification measure from Study 1.

We, however, take a second explanation to be more plausible. On this interpretation, we must draw a distinction between the justification to claim your right to rebuke and your standing to hold such a right. This is a point made by Gilbert who claims that "Standing, incidentally, must be sharply distinguished from justification. One may have the standing to demand something of someone, yet not be justified in doing so, in the circumstances" (2009, p. 177, emphasis hers). In the example Gilbert discusses, she points out that if you are acting together with someone who fails to fulfill their obligation, you only have a standing to rebuke, but there may be good reasons not to do so. If you know that your partner is particularly sensitive and will have a crisis of conscience if rebuked, it would be wrong to rebuke him. In other words, even though you have the standing to rebuke, given your knowledge of your partner's personality, actually rebuking your partner would not be justified. Gilbert's discussion of the issue suggests a range of factors that may limit justification (2006, p. 147; 2009, pp. 177-178). Nonetheless, Gilbert holds that the presence of a joint commitment explains not only the standing to rebuke but also the occurrences of such rebukes (2006, p. 148).

We may then draw a parallel to the case developed in our experiment. The results suggest that the participants do not strongly think that Will is justified in rebuking Alexander, but this may be due to another factor, such as the fact that Alexander is helping Will. The presence of helping behavior may influence judgments about justification. Because Alexander voluntarily undertakes some action on Will's behalf, they are on unequal moral terms, and this may affect the normativity associated with the specific action. Thus, although Will may have the standing to rebuke Alexander, he shouldn't, all things considered, because Alexander has voluntarily assisted him.

Second, notice that this issue did not arise in Study 1. One possible explanation for this is the change of perspective. In Study 1, the normative relation is viewed from the perspective of the person doing the helping. Because of this, any notice from the helper that he is leaving is likely to be seen as a positive gesture, and in turn, generate a positive response. However, in Study 2 we are viewing the normative relation from the perspective of the person who owes the other person; thus calling out appears to lack the appropriate gratefulness. It may be interpreted negatively and result in an unwanted response. Because of this possibility, only people who are convinced that Alexander and Will are acting together are willing to take the risk. One possible effect of this is that the more participants take Alexander and Will to be acting together, the more they take the right to rebuke to be

\footnotetext{
${ }^{13}$ Kruskal-Wallis test across all conditions: $H(2)=5.56, p=.062, E_{R}^{2}=.04$; Mann-Whitney $U$ test between control and low joint action conditions: $U=912.5, z=-2.36, p=.018, r_{m}=.24$.
} 
justified. This explanation is also partially supported by a positive correlation between participants' judgments of togetherness and their scores on our acceptability to rebuke measure $\left(r_{s}=.139\right.$, $p<.05)$. That is, participants who saw the actors as working together gave higher scores on our acceptability to rebuke measure.

Due to these two considerations, the results do not appear to speak decisively against a normativist view that includes a distinction between justification and standing, and it remains unclear which interpretation is correct. One way to clarify this issue is to consider a case in which claiming the right to rebuke is more likely to be justified. Given the proposal above, such a case should involve people acting together on neutral terms, and avoid actions in which one party is helping another. To see whether helping has a genuine effect on justification, we developed our next two studies.

\section{3 | STUDY 3: THE RIGHT TO REBUKE IN THE WALKING CASE}

In this study, we introduced a new vignette that directly represents the disagreement between Gilbert and Bratman discussed in the introduction. Because Bratman takes walking together to be a case of modest sociality that does not generate normative relations and Gilbert takes it to be a paradigmatic case of joint action that does generate such relations, this is the vignette that most directly bears on that debate. Furthermore, by considering a case in which neither actor is helping the other, we can more clearly isolate the normative relations that exist between members of the group without the interference of external moral considerations.

This study has two central aims. First, by focusing specifically on the example Bratman provides we can determine whether normative relations are present in cases of modest sociality. Along with the normativists, we hypothesize that judgments regarding the acceptability of a rebuke will increase when there is evidence of joint action. Second, this study, which includes actors on equal terms, sheds light on the issues raised in Study 2 regarding the dampening effects of helping behavior on the justification to rebuke. If there is no increase in the acceptability of rebuke between control and joint action conditions, it suggests that the normative relation may not be bidirectional as justification becomes a less relevant issue. On the other hand, if there is an increase in acceptability, it suggests that helping behavior influences justification.

\section{1 | Methods}

One hundred and sixty American adults (43\% self-identified as female) were recruited online via Amazon Mechanical Turk. Nineteen additional participants were excluded from analyses for failing to complete the study.

As with previous studies, participants were randomly assigned to one of three conditions, producing a $3 \times 1$ between-subjects design. Fifty-three participants were assigned to our control condition, with 56 and 51 individuals assigned to our low and high joint action conditions, respectively.

Our conditions in this study vary the strength of behavioral signals and cues among two people that are walking together (q.v., Appendix S2 for the full prompts). In the control condition, participants read a prompt where two people are independently walking down 5th Avenue and, starting at 65th street, they walk beside each other, until, as it happens, one of them peels off at 59th street. In the low joint action condition, they walk together the same distance, but they "spot one another" at 65th street and then briefly walk together, chatting, until one of them peels off at 59th street. In the high joint action condition, in addition to spotting each other and chatting, they laugh and maintain 


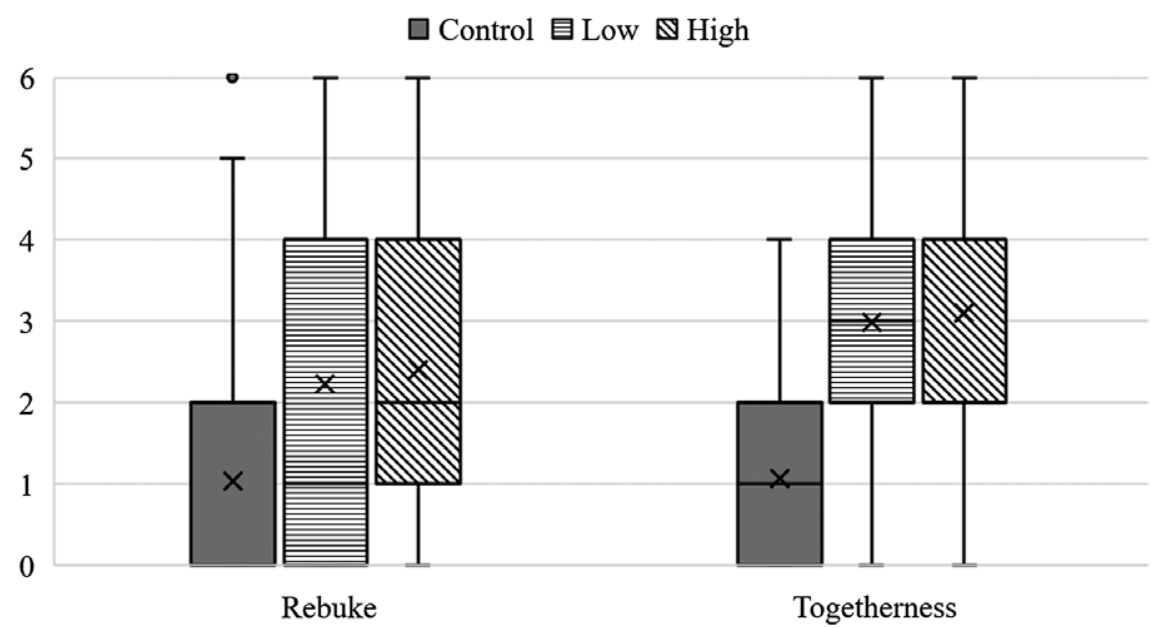

FIGURE 3 Box-and-whisker plot comparing dependent measures across our three conditions in Study 3. Bolded horizontal lines represent the medians of our measures, while "X" represents the means. Points represent furthest outliers where available

their pace. After reading the word prompts, participants are directed to answer two dependent measures displayed in random order and detailed below, and a series of demographic questions:

1. Togetherness measure: "To what extent were the two people acting together?", anchored at 0 ("Not at all") and 6 ("Totally working together").

2. Rebuke measure: "Does the person who stays have the right to call out the person who peels off?", anchored at 0 ("No right at all to call out") and 6 ("Total right to call out")

\section{2 | Results}

Consistent with our previous studies, participant scores were not normally distributed (normality tests for all our measures $p<.05)$. Participants successfully tracked increasing evidence of joint action across our conditions, as corrected pairwise comparisons of participant scores for our togetherness measure significantly increased between our control $(M d n=1)$ and our low $(M d n=3)$ and high $(M d n=4)$ joint action conditions (both $p<.001$, and $r \geq .51$; see Figure 3 and Appendix S1, Table 3). ${ }^{14}$ Median scores between our two joint action conditions were not statistically different from one another.

Increasing evidence of joint action among our vignettes resulted in an effect on our rebuke measure, $H(2)=15.39, p<.001 .^{15}$ That is, participants in either of our joint action conditions judged the acceptability of rebuke to be higher than in the control condition. ${ }^{16}$ However, as with our togetherness measure, scores between our two joint action conditions did not significantly differ.

Our measures showed a significant positive correlation with one another $\left(r_{s}=.513, p<.001\right)$. That is, participants who judged that the actors were walking together were far more likely to also judge that there was standing to rebuke. These results led us to test whether these judgments of togetherness are mediating judgments of rebuke.

${ }^{14}$ Kruskal-Wallis independent samples measures: $H(2)=42.15, p<.001, E_{R}^{2}=.26$.

${ }^{15} E_{R}^{2}=.09$.

${ }^{16}$ Corrected pairwise comparisons $p<.01, r \geq .28$. 


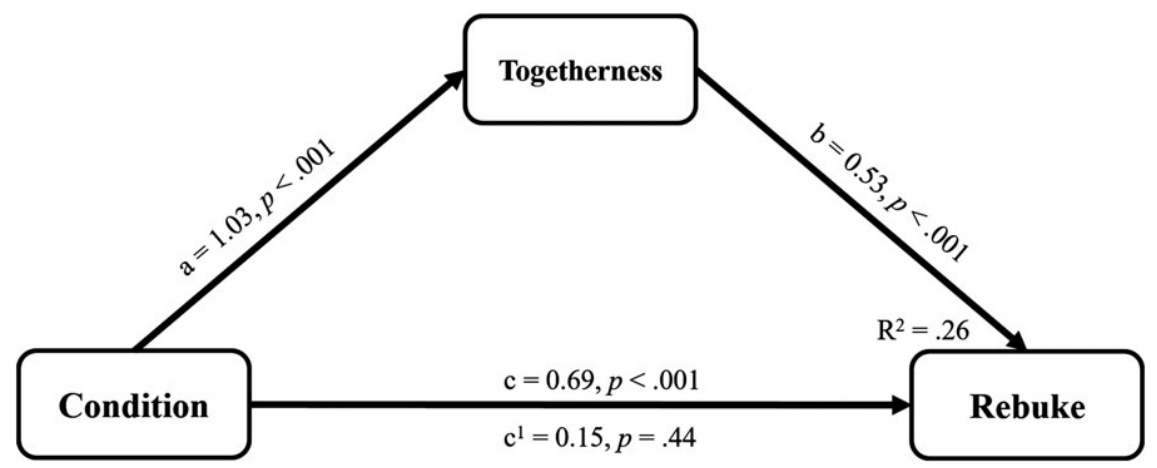

FIGURE 4 Mediation analysis for Study 3

\section{3 | Mediation analysis}

We conducted a single mediation analysis as described by Hayes (2013). ${ }^{17}$ Togetherness scores were used as the sole mediator, with our conditions serving as the independent variable and rebuke scores serving as our dependent measure. We performed our mediation via 5,000 bootstrapped samples in PROCESS (Hayes, 2013) (see Figure 4). We found a significant indirect effect of our conditions on rebuke scores through participants' judgments of togetherness, $a b=0.542$, (95\% CI: 0.295, 0.859). Our mediator could account for nearly $80 \%$ of the total effect $\left(P_{\mathrm{M}}=.785\right)$. We performed a Sobel test that confirmed this strong partial mediation $(z=4.45, p<.0001)$. Following Rose and Nichols (2013), we verified this model by comparing our findings to a model that reversed the mediation, using rebuke scores as a mediator on togetherness scores-the reverse model could only account for $25 \%$ of the total effect.

\section{4 | Discussion}

These results generally conformed to our predictions. In this case of minimal sociality, centering on two people who just happen to walk parallel to each other for a stretch of blocks, we still find that increasing evidence of joint action via subtle behavioral cues will result in a robust shift of participants' intuitions such that they infer the existence of normative relations (e.g., a right to rebuke). Though the medians for participants' judgments of the right to rebuke never approached ceiling, the difference between medians in the control condition $(M d n=0)$ and the low joint action condition $(M d n=1)$ were still significant and indicative of a moderate effect $(r=.28)$. This shift is arguably cleaner and far stronger than the shift between our control and low joint action conditions in Study 2, where helping behavior may have obscured the difference. The fact that participants' scores for rebuke rarely crossed the midpoint is indicative that these cases of minimal sociality do not present sufficient evidence of one's justification to strongly rebuke another. While, again, this dampening does not demonstrate that the normative relations inherent in joint action fail to be bidirectional, it does indicate that other contextual considerations bear on the right to rebuke, and hence that the right to rebuke is somewhat dissimilar to other normative relations, such as an obligation to notify.

A possible explanation for the results of Study 2 was that participants' judgments of togetherness drove their acceptability to rebuke. In this cleaner experiment, we find that judgments of togetherness serve as a robust partial mediator of scores to rebuke. This confirms our hypothesis that the increased

\footnotetext{
17 Mediation analyses were also conducted for Studies 1 and 2, but failed to show clear effects, likely due to the presence of helping as discussed in 2.3.
} 
scores of togetherness will predict increased willingness to rebuke; a finding that fits the normativist paradigm. That is, judgments of togetherness are doing much of the work of modulating participants' intuitions about the existence of normative relations.

Finally, participants failed to track what we took to be increasing evidence of joint action between the low and high joint action conditions. It is likely that the differences between the behavioral cues used in the low and high joint action conditions were too subtle; however, this does not affect our overall findings. The point of tension between normativists and non-normativists revolves around liminal cases of mild sociality, which was successfully captured by our design.

In our next study, we aim to test the robustness of this walking vignette by reintroducing our original dependent measure testing whether there is an obligation to notify in minimal cases of joint action. At the same time, testing intuitions of obligation may help us understand whether and to what extent the normative relations of rebuke and obligation to notify are dissimilar.

\section{I STUDY 4: THE OBLIGATION TO NOTIFY IN THE WALKING CASE}

This study keeps many of the features introduced in Study 3. Word prompts, conditions, demographic questions, and comprehension check remained identical. We replaced our rebuke measure with a notification measure similar to the one used in Study 1 (i.e., a seven-point scale with the prompt, "Should the person who peels off notify the other that they're leaving?", anchored at 0 ["No obligation at all to notify"] and 6 ["Total obligation to notify"]). Given our findings from Studies 1 to 3 , we predict that participants' ratings on this measure will increase from control to joint action conditions, and the effects for this notification measure will be more pronounced than the rebuke measure used in Study 3.

\section{1 | Methods}

One hundred and seventy-one American adults (46\% self-identified as female) were recruited online via Amazon Mechanical Turk. Twelve additional participants were excluded from analyses for failing to complete the study.

As with previous studies, participants were randomly assigned to one of three conditions, producing a $3 \times 1$ between-subjects design. Fifty-three participants were assigned to our control condition, with 59 individuals assigned to both our low and high joint action conditions. The conditions and dependent measures are described in section 3.1, with our main dependent measure modified as described in 4.

\section{2 | Results}

Participant scores were not normally distributed. ${ }^{18}$ Replicating our results from Study 3, participants tracked increasing evidence of joint action between control and both joint action conditions, but not between our two joint action conditions-although this contrast was trending toward significance at $p=.06$ (see Figure 5 and Appendix S1, Table 4). ${ }^{19}$

Confirming our prediction, participants' scores for our notification measure were significantly higher in either of our joint action conditions than in our control condition, showing an effect-

\footnotetext{
${ }^{18}$ Kolmogorov-Smirnov and Shapiro-Wilk's for both measures $p<.05$.

${ }^{19}$ Kruskal-Wallis independent samples measures: $H(2)=47.61, p<.001, E_{R}^{2}=.28$; significant corrected pairwise comparisons both $p<.001, r \geq .48$.
} 


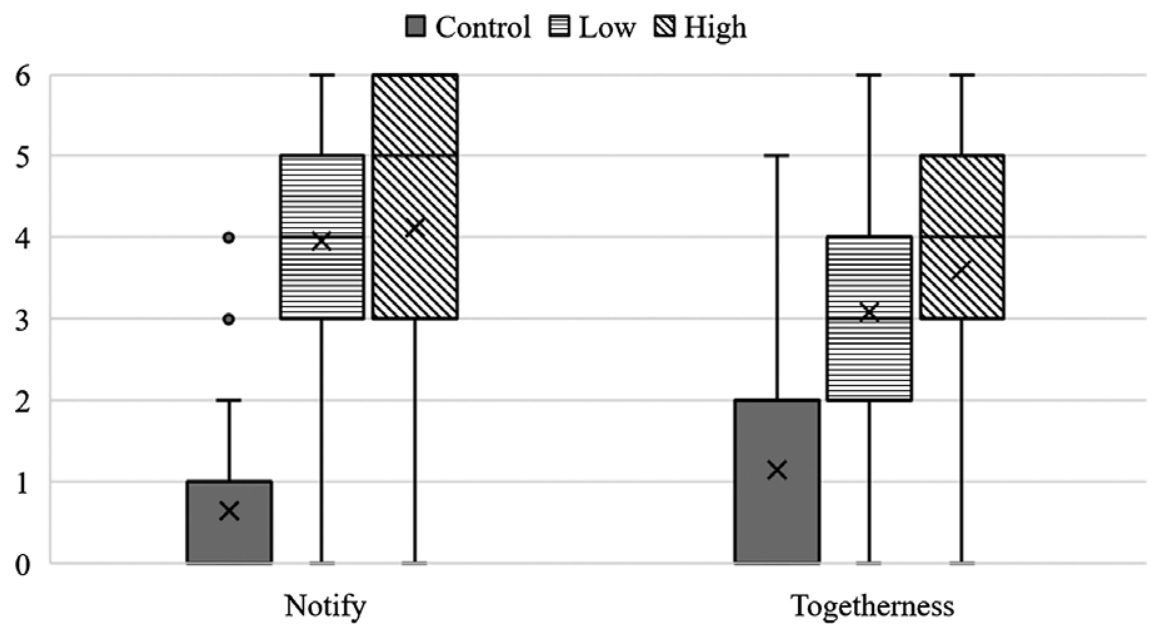

FIGURE 5 Box-and-whisker plot comparing dependent measures across our three conditions in Study 4. Bolded horizontal lines represent the medians of our measures, while " $\mathrm{X}$ " represents the means. Points represent furthest outliers

comparatively larger than with our rebuke measure in Study 3-across our conditions $H(2)=77.98$, $p<.001 .^{20}$ Again, scores between our two joint action conditions did not significantly differ.

As with Study 3, our two measures significantly correlated with one another $\left(r_{s}=.62, p<.001\right)$. This correlation led us to conduct a similar mediation analysis to 3.3, testing whether participants' judgments of togetherness may be mediating their scores on our notification measure.

\section{3 | Mediation analysis}

Following section 3.3, judgments of togetherness were used as the sole mediator, with our conditions serving as the independent variable and ratings of obligation serving as our dependent measure. We performed our mediation via 5,000 bootstrapped samples in PROCESS (Hayes, 2013). Judgments of togetherness treated as our mediator could account for nearly $40 \%$ of the total effect $\left(P_{\mathrm{M}}=.383\right)$. However, when we reversed the mediation, following the recommendations of Rose and Nichols (2013), we found that participants' scores on our notification measure served as a far stronger mediator of the effect of condition assignment on judgments of togetherness (see Figure 6). ${ }^{21}$ Our notification measure could now account for over $62 \%$ of the total effect $\left(P_{M}=.621\right){ }^{22}$

\section{4 | Discussion}

These results, again, confirm that even in minimal cases of joint action, such as the walking vignette adapted from Bratman (2006), participants infer the presence of normative relations. In effect, Study 4 replicates this finding from Study 3. Additionally, the use of a similar dependent measure tracking obligation as in Study 1 confirms that participants are especially sensitive to relations of obligation between actors involved in a joint action. At the same time, the stronger effect produced by our notification measure $(r \geq .7)$ than our previous rebuke measure used in Study 3 ( $r \geq .28)$, suggests that while participants do infer a right to rebuke in cases of joint action, this relation is somewhat dissimilar to an obligation to notify. Though we cannot directly compare the data between these two studies,

${ }^{20} E_{R}^{2}=.45$, significant corrected pairwise comparisons $p<.001, r \geq .7$.

21 Again, thanks to an anonymous reviewer for this suggestion.

$22 a b=.7495,95 \%$ confidence interval: $0.494,1$. 


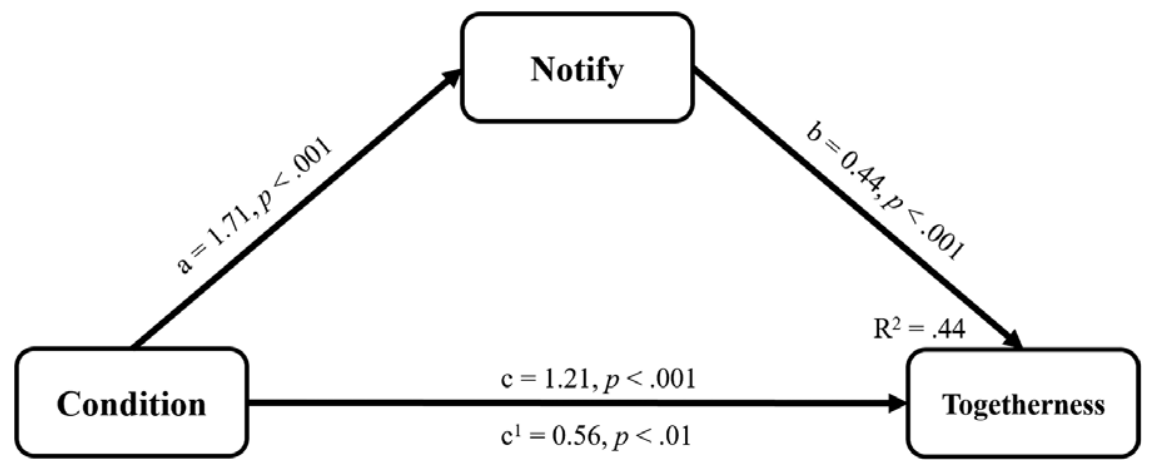

FIGURE 6 Mediation model for Study 4

it suggests that our explanation of dampening in the case of rebuke is plausible. Clearly, future paradigms should specifically target this question.

Interestingly, while togetherness scores weakly mediated our notification measure, a far stronger mediation was obtained when we reversed the model. Participants' scores on our normative measure, in this case notification, better predict their judgments of togetherness, rather than vice versa, as in Study 3. This unexpected result hints at the difference between the two normative relations we have been testing. It appears that active rebuke requires more evidence of joint action to gain justification. In other words, participants must have some confidence that the characters are together in order to think that actually rebuking another actor is justified. By contrast, it appears that the presence of an obligation serves as evidence for togetherness. Furthermore, it is possible that the presence of an obligation may then play a role in informing participants that there is standing for a socially riskier act of rebuke. Comparing Figures 3 and 5 lends some credence to this view, as scores for our togetherness measure show far more movement in Study 4 than in Study 3, even though the only modification between the two studies was the substitution of our rebuke measure with our notification measure. Future work using this paradigm may consider the value of combing these various normative measures and testing for possible ordering effects - the possibility of which was eliminated in our design by the random presentation of measures. Obtaining confidence ratings from participants, perhaps even altering the paradigms to suite the methods of signal detection theory, may also be promising leads.

Investigating the differences and relations between our various normative judgments is a fascinating further project. However, for the purposes of this paper, we focus on the strength of association between these judgments. The mediation analyses reveal the causal relationships between the judgments of our participants, but the direction of these relationships does not fully determine the conceptual relationship between normative relations and acting together. ${ }^{23}$ If normative relations are part of our concept of acting together, as the normativist claims, then there will be a strong association in both directions between our judgments of togetherness and our judgments of normativity. If normative relations are not part of the concept of acting together, as the non-normativist claims, then we expect to be able to generate positive judgments about joint action without that causing positive judgments about normative relations. The strength of this association is therefore more indicative of the conceptual relationship than the direction of causality in participants' judgments. Since addressing the disagreement between normativists and non-normativists is our main focus here, we leave further exploration of the causal relationships between participants' judgments to future research.

23 Thanks are due to an anonymous reviewer for pressing us to think further about this issue. 


\section{I STUDY 5: THE ELEVATOR CASE}

All our previous studies varied behavioral evidence of acting together and then asked participants to make judgments about the presence of two kinds of normative relations: obligation to notify and right to rebuke. In this study, we reverse the paradigm; that is, we increased evidence of normative relations among two fictional actors and then checked whether participants judged that the two actors were acting together. Since this direction is less discussed in the philosophical literature, we developed our own original vignette described below (see Section 5.1 and Appendix S2 for the full prompts).

The aim of this study is to examine whether the relationship between joint action and normativity is symmetric. Given our previous results, we predict that if the normativist account is robust, then participants will infer from evidence of normative relations that the characters in our vignette are acting together.

\section{1 | Methods}

One hundred and sixty-one American adults (48.4\% self-identified as female) were recruited online via Amazon Mechanical Turk. Fifteen additional participants were excluded from analyses for failing to complete the study.

As with previous studies, participants were randomly assigned to one of three conditions, producing a $3 \times 1$ between-subjects design. Fifty-three participants were assigned to our control condition, with 54 individuals assigned to both our low and high normativity conditions.

Since our goal is to verify whether the relationship between perceived togetherness and normativity is symmetric, our conditions increase the strength of normative cues among two fictional characters. Furthermore, we had to design the prompts so as to mitigate explicit mention or evidence of togetherness. Each of the conditions begins with an observer waiting for an elevator. Once the elevator doors open, the observer sees two men. In the control condition, the two men simply walk out of the elevator, with the taller man following the shorter man. In our low normativity case, the shorter man glances back at the taller man behind him, causing the taller man to speed up. We take this manipulation to demonstrate a gentle rebuke to the slower man for lagging behind in the sense described by Gilbert (2006, p. 148). In the high normativity condition, the shorter man turns back to the taller man and says "Come on, hurry up!", clearly rebuking him for his slowness. Following the prompts, participants are then asked two questions that correspond to our dependent measures (presented in random order and listed below), after which they answer a series of demographic questions:

1. Regulation measure: "To what extent is the shorter man trying to regulate the behavior of the taller man?" anchored at 0 ("Not at all") and 6 ("Completely").

2. Togetherness measure: "To what extent were the two men acting together?," again presented on a seven-point scale identical to the one used above

\section{2 | Results}

As we have come to expect with previous variants of this paradigm, participant scores were not normally distributed. ${ }^{24}$ Participants correctly tracked our manipulation of increasing evidence of normativity. Corrected pairwise comparisons of median regulation measure scores between our control

${ }^{24}$ Kolmogorov-Smirnov and Shapiro-Wilk's for both measures $p<.05$. 


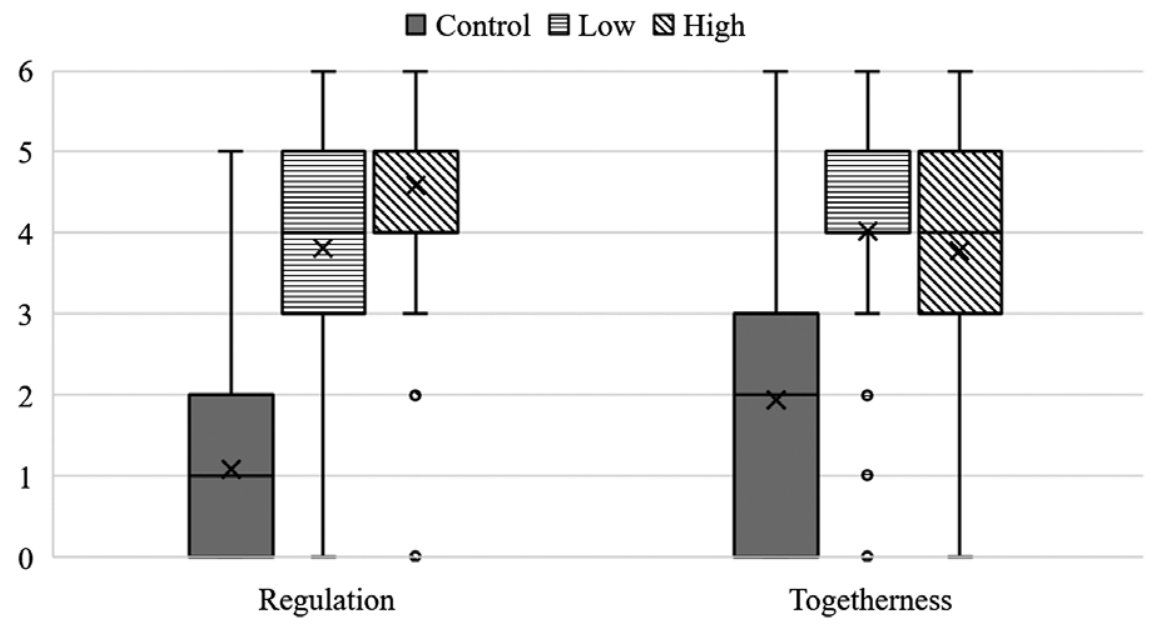

FIGURE 7 Box-and-whisker plot comparing dependent measures across our three conditions in Study 5. Bolded horizontal lines represent the medians of our measures, while " $\mathrm{X}$ " represents the means. Points represent furthest outliers

condition (1) and either our low (4) or high (5) normativity conditions were significantly different (both $p<.001$, and $r \geq .63$; see Figure 7 and Appendix S1, Table 5). ${ }^{25}$ Scores in our two normativity conditions were significantly different from one another when left uncorrected for multiple comparisons. $^{26}$

Following our predictions, participants' scores for our togetherness measure were significantly higher in either of our normativity conditions than in our control condition, $H(2)=36.67$, $p<.001 .^{27}$ At the same time, corrected pairwise comparisons showed that there was no significant difference in scores between our low and high conditions (both $M d n s=4$ ). Furthermore, these two measures were significantly correlated with one another $\left(r_{s}=.407, p<.001\right)$. Mediation models were constructed to help determine which of our measures served as the strongest predictor.

\section{3 | Mediation analysis}

First, we treated scores from our regulation measure as the sole mediator, with our conditions serving as the independent variable and ratings of togetherness serving as our dependent measure. We performed our mediation via 5,000 bootstrapped samples in PROCESS (Hayes, 2013). We found a substantial and significant indirect effect of our conditions on ratings of togetherness through participants' judgments of regulation, $a b=0.542$, (95\% CI: 0.176, 0.923). Our mediator could account for nearly $60 \%$ of the total effect $\left(P_{\mathrm{M}}=.594\right)$. We also performed a Sobel test that confirmed this partial mediation $(z=3.242, p=.0012)$. A reversed mediation, treating togetherness measures as our sole mediator, as we did in section 3.3, could only account for $11 \%$ of the total effect see (Figure 8).

\footnotetext{
${ }^{25}$ Kruskal-Wallis independent samples measures between conditions: $H(2)=83.71, p<.001, E_{R}^{2}=.52$.

${ }^{26}$ Uncorrected $p$ value $=.023$, corrected value adjusted for six multiple comparisons (a conservative adjustment) nearly reached our threshold for significance $(p=.068), r=.21$.

$27 E_{R}^{2}=.22$.
} 


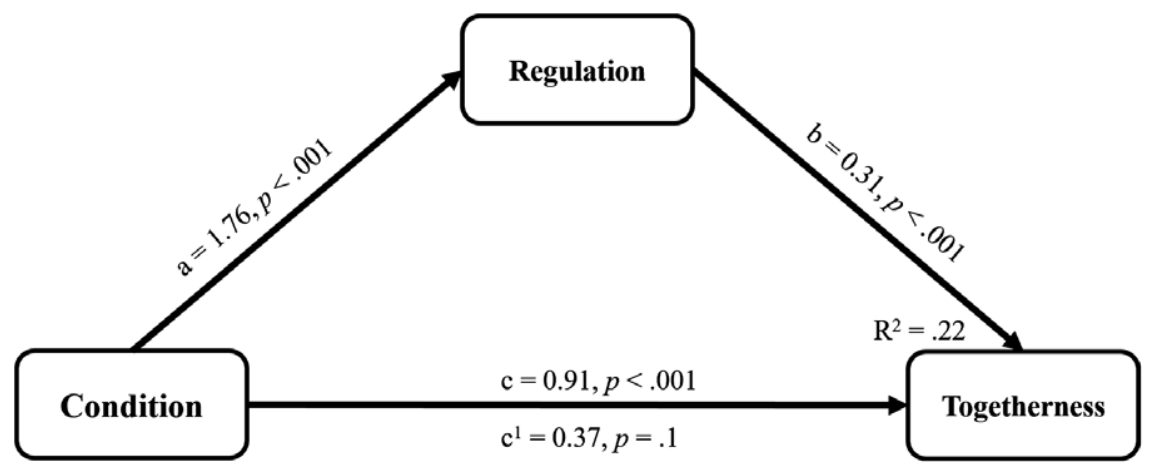

FIGURE 8 Mediation model for Study 5

\section{4 | Discussion}

This study indicates that the relationship between normative relations and instances of joint action is symmetric; that is, evidence of normativity is concomitant with inferences of togetherness. Additionally, the manipulations we provided in our vignette to increase evidence of normativity were robust enough to be easily tracked and identified by participants.

At the same time, increased evidence of normativity did not correspond linearly with increased judgments of togetherness between the low and high normativity conditions. There are a few possible explanations for this relation. While normative relations between agents may serve as a strong cue that they are acting together, there may be a ceiling effect to this correlation; that is, more contextual evidence of a different sort might be needed to push individuals' judgments of togetherness even higher. Future designs should consider how to test this hypothesis against the risk of explicitly mentioning togetherness in the relevant prompts. However, if we review Studies 1 and 2, we see that successfully increasing evidence of joint action from the low to high conditions did not significantly increase judgments of normativity - a kind of inverse pattern to what we find in Study 5. It appears that the initial, minimal, presence of joint action implies normativity and vice versa, while increasing only evidence of either joint action or normativity after this liminal point does not necessarily translate into higher ratings of the second measure.

\section{I STUDY 6: THE ATM ROBBING CASE}

Both normativists and non-normativists allow that there are often normative relations involved in joint action. The difference lies in whether they take these relations to be an inherent part of acting together. On the non-normativist side, this claim is often rejected by holding that whatever normativity is present in joint action, it is a matter of general morality. Consider the following quote from Bratman: "such temporally extended interactions among the participants [in a joint action]...frequently engage familiar norms of moral obligation" (2013, p. 110). Because these are moral obligations, they do not hold in cases in which the joint action is morally reprehensible (Bratman, 2006, pp. 151-152; 2013, pp. 110-111). On this point, Gilbert claims that "Another argument alludes to shared intentions to do something bad. Bratman assumes that these cannot involve obligations to act in favor of the shared intention. Yet those who share intentions to do bad things may well think otherwise" (2009, p. 178). Gilbert suggests here that there may be a specific kind of normativity between 
the participants of a joint action that gives them obligations to one another. These obligations are distinct from moral obligation in part because they may be present even if there is an overall moral obligation not to commit the action.

The purpose of this study is to test whether people take there to be normative relations between actors engaged in a morally questionable joint action. To this end, we have developed a novel vignette that involves taking money from an ATM (q.v., Appendix S2 for full prompts). Similar to Studies 1-4, we manipulated evidence of joint action to examine the effect this change may have on participants' intuitions of normativity. However, we also increased evidence of moral transgression between conditions. Given the results of Studies 1-4, where increased evidence of joint action between low and high conditions did not resolve into increased ratings of normativity, we reduced our conditions from three to two. If the normativist account is correct, then we would predict that participants will be sensitive to increased evidence of joint action independently of the global moral transgressions of the actors. That is, in the control condition, participants should judge that the character leaving the booth has no obligation to notify the other, while in the high joint action condition participants' scores should be reversed.

\section{1 | Methods}

One hundred and one American adults (49\% self-identified as female) were recruited online via Amazon Mechanical Turk. Four additional participants were excluded from analyses for failing to complete the study.

Participants were randomly assigned into our two conditions, producing a $2 \times 1$ between-subjects design. Fifty participants were assigned to our control condition, with 51 individuals to our joint action condition.

In our control condition, two people are lined up at an ATM booth. The machine malfunctions and \$20 bills start spraying out of the ATM. One person begins to furiously collect as many bills as possible, while the other person catches the few solitary bills that hit them, and then suddenly peels off and walks out of the booth. In our joint action condition, two people are actively breaking into an empty ATM booth late at night. One man has the crowbar and is furiously trying to take the cover off the ATM; the other man has a bag ready to collect the cash. In the middle of the process of breaking into the ATM, the bagman suddenly peels off and walks out of the booth. Afterwards, participants are directed to answer three questions, with the first two presented in random order, followed by our standard demographic questions:

1. Notification measure: "Should the person who peels off notify the other that they're leaving?" with a seven-point scale anchored at 0 ("No obligation at all to notify") and 6 ("Total obligation to notify").

2. Togetherness measure: "To what extent were the two men acting together?", along with a scale anchored at 0 ("Not at all") and 6 ("Completely").

3. Morality measure: "Were the actions taken by the two people morally wrong?", with a 7-point scale anchored at 0 ("Not at all wrong") and 6 ("Completely wrong"); this question was presented following the previous two on a separate page.

\section{2 | Results}

Participant scores across our three measures were not normally distributed. ${ }^{28}$ As our current design has only two conditions, Mann-Whitney comparisons between conditions were used along with 


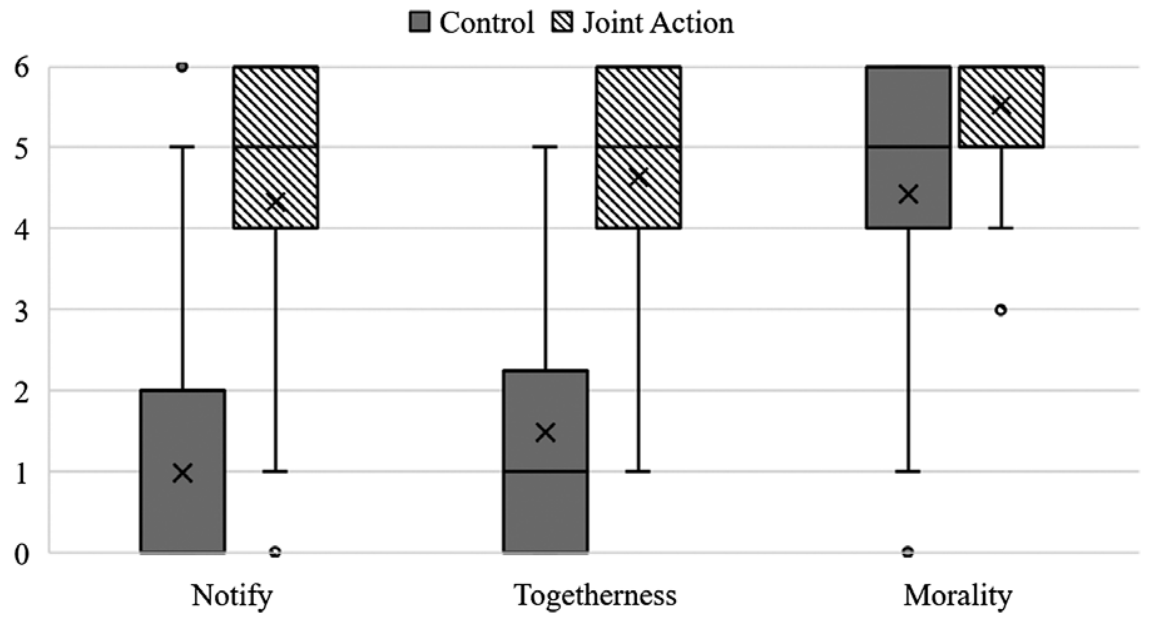

FIGURE 9 Box-and-whisker plot comparing dependent measures across our three conditions in Study 6. Bolded horizontal lines represent the medians of our measures, while " $X$ " represents the means. Points represent furthest outliers

Spearman's Rho for correlations. Participants correctly tracked both manipulations. They rated the behavior in the joint action condition $(M d n=6)$ at ceiling and thus significantly worse than in the control condition $(M d n=5)$, although they also thought that the actions in the control condition were not morally correct. ${ }^{29}$ Additionally, participants' scores for our togetherness measure were significantly higher in our joint action condition $(M d n=5)$ than in the control condition $(M d n=1) .{ }^{30}$ Most relevantly for our predictions, participants judged that the character who leaves the ATM booth had more of an obligation to notify in the joint action condition $(M d n=5)$ than in our control condition, where medians reached the floor of our measure $(M d n=0) .{ }^{31}$ Though all of our measures were significantly correlated with one another, the strongest relationship was found between our togetherness and notification measures $\left(r_{s}=.561, p<.001\right)$. Following our predictions, individuals who gave lower ratings of togetherness were less likely to think that there was an extant obligation to notify, and vice versa. ${ }^{32}$

\section{3 | Discussion}

As our results show, in both conditions participants thought the actions undertaken by the characters were morally wrong; however, in the joint action case the actions undertaken were seen as significantly worse. The general findings of this study do support the view that there is a distinct kind of normativity present between contributors to a joint action that operates independently from general moral considerations. Our findings suggest that even when people are working together toward questionable goals there are still significant normative relations between them. ${ }^{33}$

At the same time, the present design suffers from some limitations. Because we did not vary moral valence independently of joint action-which would have required a $2 \times 2$, or $3 \times 2$ design if

${ }^{28}$ Kolmogorov-Smirnov and Shapiro-Wilk's for all measures $p<.05$.

${ }^{29} U=738.5, z=-3.953, p<.001, r_{m}=.39$.

${ }^{30} U=280, z=-6.862, p<.001, r_{m}=.68$.

${ }^{31} U=309, z=-6.78, p<.001, r_{m}=.67$. See Figure 9 for a graphical representation.

32 Mediation models were constructed but none of them yielded significance; as condition assignment was the strongest predictor of both our togetherness and notification measures which makes intuitive sense given that there are only two conditions.

33 One alternative explanation is that there is only an appearance of obligation resulting from a betrayal of trust between the characters. Future extensions of this paradigm might ask participants to give confidence ratings to determine the strength of the judgment that there is a genuine obligation. 
one includes a neutrally valenced case-we cannot rule out that the negative moral valance of the action in our vignette served as a confound; that is, that negative moral situations may produce normative relations identical to those that were produced in our previous joint action manipulations. However, even this alternative explanation of the presence of normative relations in these vignettes forms a challenge to non-normativist intuitions as it would suggest that normative relations between participants strengthen proportionally with the moral wrongness of that action. Furthermore, this explanation is unlikely, as participants still judged the behavior in our control condition to be morally problematic - thus, the driver of judgments of normativity is likely to be connected to joint action and not the moral considerations at play.

\section{7 | GENERAL DISCUSSION}

Across our studies, we find support for the general thesis that normative relations are robustly associated with joint action, which in turn suggests that, according to our common intuitions, normative relations are inherent in joint action. This holds true both for the obligation to notify (Studies 1 and 3 ) and the right to rebuke (Studies 2 and 4), for cases involving helping (Studies 1 and 2) and neutral cases (Studies 3 and 4), for the reverse direction (Study 5), and for cases in which the joint action is morally dubious (Study 6). Although general moral considerations, such as helping behavior, did influence the normative relations between the contributors to the joint action, as in Study 2, this dampening effect did not preclude them.

\section{1 | Consequences for the debate between Bratman and Gilbert}

While these results support the normativist thesis in general, the implications for the specific debate are less clear. While both Gilbert and Bratman do not claim that actors in joint actions must believe that there are particular joint intentions or commitments between themselves (Bratman, 2013, pp. 114-115), they do both employ a descriptive methodology that relies on our intuitions about actual cases of acting together in order to argue that there are these joint intentions or commitments present in cases of joint action. Furthermore, they do not provide an alternate method of determining the constitutive features of joint action. We attempt to model this methodology in our vignettes by asking the participants about their intuitive judgments rather than about the presence of obligations or rights directly. Thus, determining whether it would be acceptable or not to walk away or call out reveals the implicit understandings of the normative relations amongst the joint actors rather than participants' explicit beliefs about those normative relations. Both Bratman and Gilbert attempt to do the same with the intuition-pumps they provide to motivate their philosophical arguments.

If these behavioral cues do track implicit understandings of normative relations, two of our central findings speak against Bratman. First, even in Bratman's paradigmatic walking together case, participants judged that there was both an obligation to notify and a right to rebuke. As Bratman's argument relies on there being cases of modest sociality that involve joint intentions but no distinctive normative relations (2013, p. 107), the fact that one of his favorite examples does involve normative relations suggests that his model of joint action is mistaken. It is important to highlight that some non-normativist thought experiments do not generate the intuitions that they are supposed to. People do not have the intended intuitions about these cases, and, at the moment, there is no empirical evidence about cases that support a non-normativist view. However, our results obviously do not definitively prove that no such cases exist. There may be other examples that better fit a non-normativist view. Nonetheless, it seems that, at least for the debate between Bratman and Gilbert, our studies shift 
the burden of proof back onto Bratman to detail an example of modest sociality that does not involve obligations and rights. At the same time, such a move would lend credence and validate our methodology of testing intuitions. Second, these results suggest that there are at least two separate kinds of normativity, a point that Bratman denies (2013, pp. 111-113). As Bratman makes clear, on his view, any obligations that arise in joint actions are familiar moral obligations. At the same time, it seems difficult to square this with the intuition that one ATM robber has an obligation to notify the other that they are going to leave (Study 6). If all that's involved is moral obligation, then the obligation that the ATM robber has is to terminate the immoral act as quickly as possible.

While these considerations do speak against Bratman's view, it is not clear that they are fully in line with Gilbert's view of what these normative relations are. According to Gilbert, a joint action involves a joint commitment, and joint commitments come with a series of normative consequences, which we have not tested here (2006, 2009, 2013). For example, joint commitments, unlike personal commitments, cannot be rescinded unilaterally, which means that a joint commitment can only be terminated jointly (2013, p. 32). With respect to joint intention, Gilbert states this in terms of the "concurrence criterion":

An adequate account of shared intention will entail that, absent special background understandings, the concurrence of all parties is required in order that a given shared intention be changed or rescinded, or that a given party be released from participating in it (2009, p. 173).

Our studies concern the obligation to notify, which, while showing the presence of some kind of normative relation, is weaker than the concurrence condition, as it does not involve seeking the permission of the other party, which is what Gilbertian joint commitment requires (2013, p. 25).

Additionally, Gilbertian joint commitments create more than just obligations to notify-they create obligations to perform the contributory actions necessary for the completion of the joint action. She states that "By virtue of the existence of the [joint] commitment, and that alone, the parties have rights against each other to actions that conform to the commitment" (2006, p. 148). These rights and entitlements to rebuke suggest that each party to the joint commitment has an obligation to carry out their part in the joint action (1990, pp. 180-181). These kinds of obligations go far beyond a simple obligation to notify. Consider the bank robber case. Participants thought that there was an obligation to notify, but it is not clear that they would also think that there is an obligation to perform an action in conformance with the overall joint action of robbing the ATM.

Our motivation for choosing the obligation to notify as the relevant indicator of normative relations is that it appears to be the weakest form of normativity specific to joint action. As a result, if our studies had shown that even it was not present in cases of acting together, the non-normativist side would have a clear advantage in this debate. Additionally, the most important case in the debate between Gilbert and Bratman is the walking together case, and in his example, Bratman denies exactly such an obligation. Showing that this obligation appears to be present is a vital step forward in the debate. However, it leaves many questions open about the type of normativity involved.

One natural objection to our results concerns the epistemic role and weight of empirical investigations of philosophically relevant intuitions. Though Tollefsen and colleagues have recently provided a defence of the empirical examination of intuitions in social philosophy, particularly concerning joint action, normativists may suggest that their investigations into joint action aim at metaphysical truths that escape from, or fail to reflect, folk intuitions (Tollefsen et al., 2014, pp. 250-251). The implication of this claim is that research on the content and psychological genesis of intuitions can neither adjudicate between, nor serve as sound premises in, metaphysical theories of joint action. 
There are at least two reasons to resist this conclusion. First, a wholesale denunciation of intuitions jeopardizes the non-normativist project. Non-normativist arguments often depend on the evidentiary status of thought experiments that aim to drive our intuitions about the normative status of joint actions. If those thought experiments fail to drive the relevant intuitions, as we have discovered in our work, it then gives non-normativists cause to refine their thought experiments or proffer testable explanations for why it is that they failed to elicit the relevant intuitions. We should recognize that these cycles of testing and refinement can only help to narrow and strengthen the evidentiary foundations of whatever theory results. Rejecting such cycles commits one to a theory that is autonomous and decoupled from the agents that realize it, leaving it, in principle, untestable and unfalsifiable.

The second reason to resist a rejection of intuitional methodologies is that the genesis of folk intuitions is a relevant philosophical question in its own right (Knobe \& Nichols, 2008, p. 14). Correlating how people generate and alter their intuitions with changes in word prompts, or stimuli more generally, gives us purchase on the kinds of mental and psychological mechanisms that underwrite the phenomena at hand. Given that we are focused on joint action, a phenomenon that involves intersubjective interaction, such a psychological project is especially germane. As we discuss in the following sub-section, understanding the psychological systems that are involved in recognizing and moderating joint action is at least one important avenue for further research that would be limited by a rejection of intuitional methods.

\section{2 | Further research directions}

These considerations, along with the framework and paradigms devised in our studies, open significant areas for further research. By conducting future studies we can determine more precisely whether our common intuitions support a Gilbertian view of normative relations between participants or some other, perhaps weaker, form (Roth, 2004, 2014). Normativists have done extensive work clarifying the nature of the normative relations involved in joint action. For example, both Gilbert and Roth argue that the obligations in joint action are directed at specific individuals, and can be characterized in terms of ownership not present for third-parties (Gilbert, 2006, pp. 35-41; Roth, 2004, p. 364). Determining whether participants pick up on the possible directed nature of these normative obligations is a clear avenue for further extensions of our work. One possibility would include recording participants' written answers to our prompts. With the rigorous application of coding schemata, along with the use of coders who are blinded to our hypotheses, we may be able to categorize and understand the range of motivations underlying our effect.

Another important consideration is that our vignettes were framed in third-personal language, while the story is told in the second person in Bratman's original example. Glancing through the common thought experiments given in the literature, it appears that stories meant to elicit normative intuitions are usually told in the third person, and those meant to elicit non-normative intuitions are usually told in the first or second person. ${ }^{34}$ As a result, it is worth exploring whether we are generally normativists in the third person and non-normativists in the first and second person, giving rise to a pluralist account of joint action.

Additionally, it may be fruitful to test whether these same kinds of normativity are similarly instantiated in other cultures. It is possible that the norms that govern joint action are culturally

\footnotetext{
${ }^{34}$ Compare, for example, the car pushing case from Searle (1990, p. 3), or the walking case in Bratman (2006, p. 7; 2013, pp. 107-109), as well as his later discussion (2009, pp. 151-152), all of which are couched in first or second personal language, to the original walking case in Gilbert (1990, pp. 2-9) and her other examples (2006, pp. 103-124; 2009, p. 168ff; 2013, p. 24ff), which are all in the third person. Thanks to Bryce Huebner for pointing this out to us.
} 
dependent, and that our particular responses to our partner's contributory actions or lack thereof is socially conditioned. Testing for the presence of such norms against distinct social and cultural backgrounds may provide important evidence about the relationship between our biological nature, how we act together, and the social and cultural practices we develop. Relatedly, further research should also be conducted on larger groups involved in joint actions. All our cases deal with dyads. There may be important differences in the strength of normativity between two people acting together and larger joint actions involving division of tasks, spatial distance, mediated communication, and so on.

Another direction for continuing research focuses on how deeply-seated these normative relations are. Research (Tomasello, 2009; Tomasello \& Racokzy, 2003) suggests that the capacity for joint action, as related in the philosophical literature, is present very early on in human development and may be the distinctive mark of human beings. Although he is noncommittal about exactly which account of joint action he accepts (Schmid, 2012), he seems to favor a two-step model, in which there is a basic ability at an early stage based on the non-normativist account of Searle, and a more developed version that arises later in development and includes Gilbertian normativity. Supplementary investigation of the association between joint action and normativity in human cognition engenders the possibility of fruitful collaboration with developmental, evolutionary, and neuroscientific perspectives.

Continuing this empirical trajectory for future research, the magnitude and robustness of our findings can be taken as evidence for the recruitment of a cognitive component involved in the identification and tracking of joint actions or commitments. Novel paradigms, for instance involving eye-tracking of stimuli, might help us uncover whether and to what extent subpersonal cognitive systems are involved in these discriminations and determinations of joint action. However, it's likely we can gain purchase on this hypothesis by modifying a simple perceptual animacy paradigm, where various colored two-dimensional shapes follow or interact with one another, similar to those devised by Michotte (1963) (Scholl \& Tremoulet, 2000). If participants are similarly sensitive to the behavioral cues implicit in "joint actions" when instantiated by lifeless two-dimensional objects, then we will have strong evidence that there are low-level cognitive components involved in these judgments.

\section{8 | CONCLUSION}

The importance of continuing empirical research into the domain of joint action is clear. What these findings already suggest, however, is that our common intuitions are in line with a general form of the normativist thesis. When two people are acting together, we seem to attribute some basic normative relations to them, and when we have evidence of some normative relations between them, we take them to be acting together. Furthermore, because this normativity is directed at the other participants in the joint action and is present even in morally questionable cases, it is distinct from general moral obligations and rights, despite being influenced by global norms. Taken together, these results support the claims that joint actions are inherently normative, and that this normativity is distinct from morality.

\section{ACKNOWLEDGEMENTS}

We would like to thank Kate Ritchie, Aaron Bentley, Richard Moore, Hagop Sarkissian, John Greenwood, Carol Gould, Jesse Prinz, Michael Pauen, along with participants at the 2017 Subjectivity, 
commitment and acting together workshop at the Berlin School of Mind and Brain and funded by the Einstein Foundation, audiences at the SSPP, ESPP, and Collective Intentionality X conferences, and two anonymous reviewers at Mind and Language for helpful comments and discussion on earlier drafts of the paper. The authors contributed equally to this work.

\section{REFERENCES}

Bratman, M. (2006). Dynamics of sociality. Midwest Studies in Philosophy, 30, 1-15.

Bratman, M. (2009). Modest sociality and the distinctiveness of intention. Philosophical Studies, 144, 149-165.

Bratman, M. (2013). Shared agency: A planning theory of acting together. Oxford: Oxford University Press.

Cova, F., Lantian, A. \& Boudesseul, J. (2016). Can the Knobe effect be explained away? Methodological controversies in the study of the relationship between intentionality and morality. Personality and Social Psychology Bulletin, 42(10), 1295-1308.

Diaz, R., Viciana, H. \& Gomila, A. (2017). Cold side-effect effect: Affect does not mediate the influence of moral considerations in intentionality judgements. Frontiers in Psychology, 8, 295.

Gilbert, M. (1990). Walking together: A paradigmatic social phenomenon. Midwest Studies in Philosophy, 15, 1-14.

Gilbert, M. (2006). A theory of political obligation. Oxford: Oxford University Press.

Gilbert, M. (2009). Shared intention and personal intention. Philosophical Studies, 144, 167-187.

Gilbert, M. (2013). Joint commitment: How we make the social world. Oxford: Oxford University Press.

Hayes, A. F. (2013). Introduction to mediation, moderation, and conditional process analysis: A regression-based approach. New York, NY: Guilford Press.

Hume, D. (1740/1976). A treatise of human nature. Oxford: Clarendon Press.

Knobe, J. \& Nichols, S. (2008). Experimental philosophy. In J. Knobe \& S. Nichols (Eds.), An experimental philosophy manifesto (pp. 3-16). New York, NY: Oxford University Press.

Meijers, A. W. M. (2003). Can collective intentionality be individualized. American Journal of Economics and Sociology, 62, 167-183.

Michotte, A. (1963). The perception of causality (Trans. T. R. Miles \& E. Miles). New York, NY: Basic Books.

Rose, D. \& Nichols, S. (2013). The lesson of bypassing. Review of Philosophy and Psychology, 4(4), 599-619.

Roth, A. (2004). Shared agency and contralateral commitments. Philosophical Review, 113(3), 359-410.

Roth, A. (2014). Prediction, authority, and entitlement in shared activity. Noûs, 48(4), 626-652.

Schmid, H. B. (2009). Plural action: Essays in philosophy and social science. London: Springer.

Schmid, H. B. (2012). Shared intentionality and the origins of human communication. In A. Salice (Ed.), Intentionality (pp. 349-368). München: Philosophia.

Scholl, B. J. \& Tremoulet, P. D. (2000). Perceptual causality and animacy. Trends in Cognitive Science, 4(8), $209-309$.

Searle, J. (1990). Collective intentions and actions. In P. Cohen, J. Morgan \& M. Pollack (Eds.), Intentions in communication (pp. 401-415). Cambridge, MA: MIT Press.

Searle, J. (2010). Making the social world. Oxford: Oxford University Press.

Tollefsen, D., Kreuz, R. \& Dale, R. (2014). Oxford studies in experimental philosophy. In J. Knobe, T. Lombrozo \& S. Nichols (Eds.), Flavors of 'togetherness' (Vol. 1). Oxford: Oxford University Press.

Tomasello, M. (2009). The origins of human communication. Cambridge, MA: MIT Press.

Tomasello, M. \& Racokzy, H. (2003). What makes human cognition unique? From individual to shared to collective intentionality. Mind \& Language, 18(2), 121-147.

Tuomela, R. (2005). We-intentions revisited. Philosophical Studies, 125, 327-369.

Tuomela, R. \& Tuomela, M. (2003). Acting as a group member and collective commitments. PRO, 18(7), 7-65.

\section{SUPPORTING INFORMATION}

Additional supporting information may be found online in the Supporting Information section at the end of the article.

How to cite this article: Gomez-Lavin J, Rachar M. Normativity in joint action. Mind Lang. 2019;34:97-120. https://doi.org/10.1111/mila.12195 
Copyright of Mind \& Language is the property of Wiley-Blackwell and its content may not be copied or emailed to multiple sites or posted to a listserv without the copyright holder's express written permission. However, users may print, download, or email articles for individual use. 